W Child - 'We can go no further': Meaning, Use, and the Limits of Language - in H. Appelqvist (ed.) Wittgenstein and the Limits of Language, Abingdon: Routledge, 2020, pp. 93-114.

\title{
'We can go no further': Meaning, Use, and the Limits of Language
}

\author{
William Child
}

Is it possible to give a substantive, non-circular account of meaning and rule-following: an account that explains what it is for someone to use a word with a particular meaning, or to follow a particular rule, in terms that do not employ the concept of meaning or the concept of following a rule? Naturalists and reductionists about meaning and rules think it is possible to give such an account. Anti-reductionists, by contrast, hold that facts about meaning and rules are basic and sui generis; they cannot be reduced to, or explained in terms of, non-semantic, non-rule-involving facts. Where does Wittgenstein stand in this debate? And is he right? I shall argue that Wittgenstein is an antireductionist about meaning and rule-following, and that anti-reductionism is the correct view to take.

Section 1 shows how the issue of reductionism and anti-reductionism about meaning and rules relates to the idea of the limits of language as it figures in Wittgenstein's post-Tractatus writings. Section 2 presents a framework for assessing the interpretative debate between reductionist and anti-reductionist readings of Wittgenstein. Section 3 argues that we cannot settle that debate on the basis of Wittgenstein's general, methodological opposition to reductionism. Section 4 presents an important argument for anti-reductionism from Remarks on the Foundations of Mathematics. Section 5 considers some putative evidence of reductionism about meaning in the Brown Book and offers an alternative, anti-reductionist interpretation. Section 6 explores the nature of Wittgenstein's anti-reductionism. It argues, first, that Wittgenstein accepts that semantic and normative facts supervene on non-semantic, non-normative facts and, second, that at many points his treatment of meaning and rules is not confined to the kind of pleonastic claims that are often taken to define non-reductionist, or quietist, positions.

\section{The Limits of Language}

The idea of the limits of language is a central theme in the Tractatus. Wittgenstein writes in the Preface that 'the aim of the book is to draw a limit to thought' and explains that it is 'only in language that the limit can be drawn' (TLP p. 3). The discussion of solipsism begins with the claim that 'The limits of my language mean the limits of my world' (TLP 5.6) and goes on to explore the implications of that claim. Elsewhere, we are told that philosophy 'must set limits to what can be thought; and, in doing so, to what cannot be thought', and that its way of setting those limits is to 'signify what cannot be said, by presenting clearly what can be said' (TLP 4.114, 4.115). And so on. By contrast, there are few comments in Wittgenstein's post-Tractatus work that explicitly mention the limits of language. But there are some. And they express a theme that runs through Wittgenstein's later work and marks an important point of continuity with his earlier writings. We can sum up that theme in a slogan from 1930: we 'cannot use language to get outside language' (PR 54).

The general idea behind that slogan is that thought and description take place within a system of concepts, categories, and standards: which is to say, within language. We cannot get outside language and think about or describe the world in a way that does not employ the concepts, categories, and standards that are built into language. So there are limits to what we can use language to do. I will mention three applications of that idea. 
W Child - 'We can go no further': Meaning, Use, and the Limits of Language - in H. Appelqvist (ed.) Wittgenstein and the Limits of Language, Abingdon: Routledge, 2020, pp. 93-114.

First, Wittgenstein insists that we cannot use language to advance general metaphysical claims about reality. As he puts it: 'Time and again the attempt is made to use language to limit the world and set it in relief - but it can't be done' (PR, 80; BT, 315.) 'Us[ing] language to limit the world' would be using it to make a general restrictive claim about the nature of reality: a claim to the effect that reality comprises only some subset of the general kinds of fact that we ordinarily take it to include. Wittgenstein's basic objection to any such view is that, in order to 'limit the world' in this way, we would need a language with which to distinguish what is genuinely part of reality from what we ordinarily but mistakenly take to be part of reality. But there is no such language: no special, philosophical language that captures the world as it really is and can be used to make our restrictive claims. (As Wittgenstein puts it elsewhere, 'philosophy doesn't use a preparatory language' (RFM 392).) The point of this Philosophical Remarks claim, that we cannot use language to limit the world, is essentially the same as the point Wittgenstein makes in the Tractatus when he writes: 'we cannot say in logic, "The world has this in it, and this; but not that"' (TLP 5.61).

Second, Wittgenstein claims that we cannot use language to characterize a connection between language, on the one hand, and the world as it is in itself, independent of language, on the other hand. As he puts it:

The limit of language manifests itself in the impossibility of describing the fact that corresponds to (is the translation of) a sentence without simply repeating the sentence.

(We are involved here with the Kantian solution of the problem of philosophy.) (CV $13,10.2 .1931)$.

If we ask what fact corresponds to the sentence ' $p$ ', Wittgenstein thinks, the only possible answer is 'the fact that $\mathrm{p}^{\prime} .{ }^{1}$ So though we can if we want conceive of meaning or representation in terms of a relation between sentences and facts (or possible facts), the relation in question is, in an important sense, a relation within language. For the facts to which sentences correspond are themselves shaped by, and individuated in terms of, linguistic categories.

Third, Wittgenstein claims that the impossibility of using language to get outside language means that 'in a certain sense, the use of language is something that cannot be taught':

Suppose I have said to someone 'A is ill', but he doesn't know who I mean by 'A', and I now point at a man, saying 'This is A'. Here the expression is a definition, but this can only be understood if he has already gathered what kind of object it is through his understanding of the grammar of the proposition 'A is ill'. But this means that any kind of explanation of a language presupposes a language already. And in a certain sense, the use of language is something that cannot be taught, i.e. I cannot use language to teach it in the way in which language could be used to teach someone to play the piano.-And that of course is just another way of saying: I cannot use language to get outside language (PR 54).

No-one could be taught to speak and understand a first language by being given an explanation of how she must use words in order to speak that language. For she could not understand the explanation unless she already understood a language: the language in which the explanation was given. By contrast, she could be taught to play the piano by being given an explanation of what she must do in order to play the piano. To understand that explanation, she must already understand the language in which it is given. But she need not already be able to play the piano. The underlying point here is the same as the point that Wittgenstein makes in the early sections of Philosophical Investigations and the Brown Book when he insists that the acquisition of one's first language cannot depend on a process of ostensive definition or explanation but must instead involve ostensive training.

Now what, if anything, do these observations about the limits of language have to do with the debate between reductionism and anti-reductionism about meaning and rules? In RFM, Wittgenstein writes: 'what the correct following of a rule consists in cannot be described more closely than by describing the learning of "proceeding according to the rule"'; 'we can go no further' (RFM 392). The point of saying that 'we can go no further' than that in describing what the correct following of a rule consists in is that we cannot give an informative, non-circular explanation of what 
W Child - 'We can go no further': Meaning, Use, and the Limits of Language - in H. Appelqvist (ed.) Wittgenstein and the Limits of Language, Abingdon: Routledge, 2020, pp. 93-114.

it is to follow a rule correctly. That is a clear statement of anti-reductionism. It is also states a limit of language: a limit to what we can use language to do. We can put the point in a way that brings out the connection between our two themes - anti-reductionism and the limits of language - by adapting the formulation Wittgenstein uses in CV 13: 'The limit of language', we might say, 'manifests itself in the impossibility of describing what the correct following of a particular rule consists in without simply employing an expression of that rule.'2

But it is one thing to make such a claim of anti-reductionism. It is another thing to justify it: to explain what reason there is for thinking that 'we can go no further' than Wittgenstein says. We will take up that question in section 4 below.

\section{Meaning and Use}

Wittgenstein says that 'the meaning of a word is its use in the language' (PI §43). ${ }^{3}$ How are we to understand that idea?

Many commentators take Wittgenstein to be advancing a kind of reductionism about meaning. On that reading, the point of the idea that meaning is use is to explain semantic facts about words (the fact that the word 'red' means red, for instance) in terms of non-semantic facts about them (the fact, for example, that people who have been through the normal training will, in appropriate circumstances, by and large produce the word 'red' in response to red things).

According to Michael Dummett, for instance, when Wittgenstein describes the use of language, what is described is the complex of activities with which the utterances of sentences are interwoven; and ... the description does not invoke psychological or semantic concepts, but is couched entirely in terms of what is open to outward view (Dummett 1978, p. 446). Paul Horwich takes the same view; Wittgenstein's 'examples of the meaning-constituting uses of words', he writes, 'are never couched in semantic or intentional terms' (Horwich 2012, p. 112). And Paul Snowdon, in a recent paper, offers a similar interpretation, arguing that Wittgenstein advances a broadly reductive or constitutive form of naturalism about meaning and rule-following (Snowdon 2018).

Other commentators, by contrast, understand Wittgenstein as an anti-reductionist about meaning and rules. They agree that, for Wittgenstein, 'there can be nothing more to an expression's having a certain meaning than its being used in a certain determinate way' (Stroud 2012, p. 26). But they maintain that the notion of 'use' in this context has to be understood in semantic or intentional terms; a description of the use of an expression that 'suffices to fix its meaning' must itself 'employ the idea of meaning' (Stroud 2012, p. 27). So all we can say about the way in which use determines meaning is this: the word 'red' means red because we use it to mean red; the words 'add 2 each time' mean add two each time because they 'are used by us to mean that two is to be added each time' (Stroud 2012, p. 27); and so on. ${ }^{4}$

Which of these interpretations of Wittgenstein conception of meaning and use is correct? In addressing that question, I shall focus on two important strands in his remarks. On the one hand, there is clear evidence of anti-reductionism in Wittgenstein's work. In particular, there are his explicit general statements of quietism and of opposition to reductionism. And there is his insistence on the impossibility of giving any non-circular account of what, say, following a particular rule consists in. On the other hand, he does not adopt the crudest or most militantly anti-reductive position. In the first place, he does not think that facts about meaning are completely independent of non-semantic facts about use; on the contrary, he has things to say about the relation between semantic facts on the one hand and non-semantic facts on the other. In the second place, when he raises questions about the difference between following a rule and merely conforming to a rule, or about the circumstances under which it is right to translate a word of a foreign language in a particular way, he does not give merely pleonastic answers but aims to say something genuinely informative. To understand Wittgenstein's position, we need to understand the relation between 
W Child - 'We can go no further': Meaning, Use, and the Limits of Language - in H. Appelqvist (ed.) Wittgenstein and the Limits of Language, Abingdon: Routledge, 2020, pp. 93-114.

these two strands in his work: the combination of anti-reductionism about meaning and rules with a willingness to describe the phenomena in a way that is not wholly pleonastic.

That combination of views is nicely expressed in a passage from RFM: 'Don't demand too much, and don't be afraid that your just demand will dwindle into nothing' (RFM 383). The passage comes in the context of a discussion of mathematics and the relation between mathematical propositions and empirical facts. But the point Wittgenstein is making applies equally to our case. On the one hand, we should not demand a reduction of semantic facts to non-semantic facts. On the other hand, we are entitled to demand some account of the relation between semantic and nonsemantic facts; and we should not be afraid that the only thing to say about that relation will be something entirely trivial and pleonastic. ${ }^{5}$

\section{Wittgenstein's Anti-Reductionist Metaphilosophy}

It might be thought that the question, whether Wittgenstein's account of meaning and rulefollowing is a form of reductionism is easily settled in the negative - and against such interpreters as Dummett, Horwich, and Snowdon. For doesn't Wittgenstein state explicitly and repeatedly that philosophy should reject all forms of reductionism? He says, for example, that 'it can never be our job to reduce anything to anything, or to explain anything. Philosophy really is "purely descriptive"' (BB 18). And he expresses a similarly anti-reductionist message when he speaks approvingly of 'That marvellous motto, "everything is what it is and not another thing"' (LC 27). ${ }^{6}$ So, it will be said, there is no question of Wittgenstein's offering an account in which facts about meaning and rule-following are reduced to, or constructed from, non-semantic, non-normative facts. To offer such an account would be to ignore his own injunction that it is not the job of a philosopher to reduce anything to anything. And it would fly in the face of his insistence that meaning and rule-following are what they are and not other things.

The prominence in Wittgenstein's work of such statements of anti-reductionism plainly carries some weight. But we cannot rest the whole case for an anti-reductionist reading of Wittgenstein's view of meaning and rules on these general disavowals of reductionism. For we cannot tell, at this level of generality, where Wittgenstein himself would draw the line between an objectionably reductionist view and an acceptable, non-reductionist view. Suppose you are giving a naturalistic account of meaning of the kind that Dummett and others attribute to Wittgenstein, in which a sign's having the meaning it does is explained in terms of its role in a complex pattern of non-semantic behaviour. And suppose that, in your view, that account of meaning is a piece of common sense: a statement of what we all ordinarily acknowledge when we free ourselves from philosophical prejudices. Then in giving your naturalistic account, you will not see yourself as reducing facts about meaning to something else. On the contrary, you will take yourself to be giving a descriptive account of meaning, as Wittgenstein requires. And you will think that any supposed features of meaning that cannot be accommodated within your naturalistic account are not genuine features of meaning at all; they are merely artefacts of a bad philosophical picture of meaning. We know from Wittgenstein's general methodological stance that he will reject any position about meaning or rule-following that he takes to conflict with our common-sense understanding of the phenomena or to involve reducing semantic and normative facts to something else. But without knowing precisely what he takes to be part of that common-sense understanding, we cannot tell which specific views he would regard as being unacceptably revisionary or reductionist.

I think Wittgenstein does reject the kind of reductionist naturalism about meaning and rulefollowing that is suggested by interpreters like Dummett, Horwich, and Snowdon. But to establish that point, we have to examine the details of his discussion of rules and meaning. There is no quick way of defending an anti-reductionist interpretation by appeal to his general statements about philosophy. ${ }^{7}$

\section{An Argument for Anti-Reductionism}


W Child - 'We can go no further': Meaning, Use, and the Limits of Language - in H. Appelqvist (ed.) Wittgenstein and the Limits of Language, Abingdon: Routledge, 2020, pp. 93-114.

In RFM 392-3, Wittgenstein gives a clear statement of anti-reductionism about rules. And he offers an argument in favour of that position. What is the argument? Is it a good argument?

Wittgenstein writes:

A language-game, in which someone calculates according to a rule and places the blocks of a building according to the results of the calculation. He has learnt to operate with written signs according to rules. - Once you have described the procedure of this teaching and learning, you have said everything that can be said about acting correctly according to a rule. We can go no further. It is no use, for example, to go back to the concept of agreement, because it is no more certain that one proceeding is in agreement with another, than that it has happened in accordance with [the] rule. Admittedly going according to a rule is also founded on an agreement.

To repeat, what the correct following of a rule consists in cannot be described more closely than by describing the learning of 'proceeding according to the rule.' And this description is an everyday one, like that of cooking and sewing, for example. It presupposes as much as these. It distinguishes one thing from another, and so it informs a human being who is ignorant of something particular. (Cf. the remark: Philosophy doesn't use a preparatory language, etc.)

For if you give me a description of how people are trained in following a rule and how they react correctly according to the training, you will yourself employ the expression of a rule in the description and will presuppose that I understand it. (RFM 392-3; I have adjusted the translation of the penultimate sentence of paragraph 1)

Paragraph 2 of that passage contains a clear, anti-reductionist message: 'what the correct following of a rule consists in cannot be described more closely than by describing the learning of "proceeding according to the rule"'. That repeats a claim made in paragraph 1: 'once you have described this procedure of teaching and learning, you have said everything that can be said about acting correctly according to a rule. We can go no further'. But what reasons does Wittgenstein have for saying this? What stops us from 'going further' and giving a non-circular, constitutive account of what it is to act correctly according to a rule?

It is important first to be clear about what exactly it is that Wittgenstein is saying cannot be reductively explained. When he talks about 'what the correct following of a rule consists in', and about 'acting correctly according to a rule', what is he referring to? We need to distinguish between two kinds of question: (a) questions about rules themselves (e.g. the question, what one must put after ' 1000 ' in order to act in accordance with the rule add 2); and (b) questions about what it is for a person to follow those rules (e.g. the question, what makes it the case that someone who puts ' 1002 ' after ' 1000 ' is following the add-2 rule, rather than merely conforming to it). Wittgenstein's concern in RFM 392-3 is predominantly with questions of type (a) rather than questions of type (b). He is concerned with the question, what it takes for an act to accord with a particular rule, rather than the question, what it takes for someone to be following that rule rather than merely conforming to it. But there is every reason to think that he has a similarly anti-reductionist approach to answering (b)-type questions.

Now what reason does Wittgenstein give for the anti-reductionist position he articulates in RFM 392-3? What prevents us describing what the correct following of a rule consists in more closely than by describing the learning of 'proceeding according to a rule'? Paragraph 3 offers an answer:

if you give me a description of how people are trained in following a rule and how they react correctly according to the training, you will yourself employ the expression of a rule in the description and will presuppose that I understand it.

How exactly is that reflection supposed to count in favour of anti-reductionism?

It might be suggested that Wittgenstein is making essentially the same point in this passage that we saw him making in the passage from PR 54 that was quoted in part 1 above. His point there was that 'any kind of explanation of a language presupposes a language already'; so we cannot use 
W Child - 'We can go no further': Meaning, Use, and the Limits of Language - in H. Appelqvist (ed.) Wittgenstein and the Limits of Language, Abingdon: Routledge, 2020, pp. 93-114.

language to teach a language to someone who does not already have one. Someone might read paragraph 3 of RFM 392-3 in a similar way, as offering the following argument. 'If you give me a description of what it is to follow a rule correctly, you will employ expressions of rules in your description. I can only understand your explanation, therefore, if I already understand the expressions of rules it contains. And I can only do that if I can already follow rules. So there cannot be a description of what it is to follow a rule correctly that could be used to teach someone how to follow rules in the first place; if she cannot already follow rules, she will not understand the explanation.'

That argument, however, does not show that it is impossible to give a reductive explanation of what it is to follow a particular rule correctly: to act correctly according to that rule. For consider. Suppose for the sake of argument that there was some correct, non-circular, reductive account of what it is to follow a particular rule correctly: say, an account on which what counts as following the rule correctly at a particular step is defined in terms of the responses given by the majority of people who have been through a certain training. ${ }^{8}$ And suppose we agree that in order to understand that account, we would already have to be able to follow rules. ${ }^{9}$ It follows that we couldn't use the reductive account to teach someone how to follow rules in the first place. But that would not prevent it being a successful reductive account. The requirement for a reductive account of rules is that it should explain what counts as following a given rule correctly in terms that do not simply presuppose it. There is no requirement that it should be something that could be used to impart the ability to follow the rule to someone who could not already follow any rules. ${ }^{10}$

However, it is a mistake to read the argument of RFM 392-3 paragraph 3 in the way just sketched. Wittgenstein is indeed offering an argument against the possibility of a reductive account of what the correct following of a rule consists in. But his argument is different. His fundamental point is that the only way to specify what it is to follow a particular rule correctly is to use an expression of that very rule. That is a point he makes in many places. For example:

How does one describe the process of learning a rule? - If A claps his hands, B is always supposed to do it too. Remember that the description of a language-game is already a description (RFM 320).

His point is this. When I describe the process of learning a particular rule, I must say what it is that the learner is learning to do. That requires saying what counts as acting correctly according to the rule she is learning. In the current case, we can suppose that the rule B is learning is this: 'Whenever A claps a rhythm, clap the same rhythm'. Call that 'the Clapping Rule'. What counts as acting correctly according to the Clapping Rule? The obvious answer is: when A claps a particular rhythm, clapping the same rhythm. Wittgenstein's point is that that answer is true, but that it does nothing to explain what it is to clap the same rhythm as A; it simply takes that for granted. And, he thinks, the same will be true for any other answer we might give. The only way of describing what counts as acting correctly according to the Clapping Rule is to employ some expression of the Clapping Rule itself. As we put it above: the limit of language manifests itself in the impossibility of describing what following a particular rule consists in without simply employing an expression of that very rule. It is impossible to give a non-circular, reductive account of what it is to act correctly according to a particular rule.

That is the argument that Wittgenstein articulates in paragraph 3 of the RFM 392-3 passage. It is also the argument that he offers in paragraph 1, where he says that 'It is no use . . to go back to the concept of agreement, because it is no more certain that one proceeding is in agreement with another, than that it has happened in accordance with [the] rule'. ${ }^{11}$ Suppose someone offers an account like this: What it is to follow the Clapping Rule correctly in a particular set of circumstances is to behave in a way that agrees with the way A has behaved in those circumstances. As before, that claim is true. But it does not explain what it is to follow the Clapping Rule in terms that do not presuppose it. For what it is for S's behaviour to agree with A's behaviour is no simpler or more basic than what it is for S's behaviour to be in accordance with the Clapping Rule. We cannot use the 
W Child - 'We can go no further': Meaning, Use, and the Limits of Language - in H. Appelqvist (ed.) Wittgenstein and the Limits of Language, Abingdon: Routledge, 2020, pp. 93-114.

idea of agreement to give a reductive explanation of what correctly following the Clapping Rule consists in.

These remarks of Wittgenstein's state an anti-reductionist view: the only way of specifying what it is to follow a particular rule correctly is to employ an expression of that very rule. But does he offer an argument for that claim; or does he simply assert that it is true? In other passages, he mentions a range of possible reductive accounts. For instance:

The question arises, what we take as [the] criterion of going according to the rule. Is it for example a feeling of satisfaction that accompanies the act of going according to the rule? Or an intuition (intimation) that tells me I have gone right? Or is it certain practical consequences of proceeding that determine whether I have really followed the rule? (RFM 319).

Each of those suggestions ('a feeling of satisfaction', 'an intuition', 'certain practical consequences') points to a candidate reductive account: an account that aims to spell out what it is to act correctly according to a particular rule in terms that do not presuppose it. But Wittgenstein thinks that each account is obviously unsatisfactory. In the first place, they get the extension of the rule wrong. Acting with a feeling of satisfaction, for example, is neither necessary nor sufficient for acting in accord with a rule: we sometimes have feelings of satisfaction when we fail to act correctly according to the rule we are trying to follow; and we do not always have feelings of satisfaction when we succeed in following the rule correctly. And similarly for the other proposals. In the second place, the candidate accounts go wrong by making it an empirical issue what counts as applying the rule correctly in a particular case. As Wittgenstein puts it, if one of these proposals were correct:

it would be possible that $4+1$ sometimes made 5 and sometimes something else. It would be thinkable, that is to say, that an experimental investigation would show whether $4+1$ always makes 5. (RFM 319)

But those things are obviously not possible and not thinkable. That is to say, these reductive accounts fail to capture the internal or conceptual character of the connection between a rule and what counts as acting correctly according to the rule. And, Wittgenstein thinks, the same problems will arise for any other reductive account. ${ }^{12}$ Admittedly, he does not offer a proof that there could be no successful reductive account. But anti-reductionist positions can rarely be established by proof. The anti-reductionist can demonstrate the inadequacy of particular reductionist proposals by producing counter-examples. Beyond that, however, the case for anti-reductionism must rest on the plausibility of the claim that the failure of those particular proposals is symptomatic of a general problem with any reductionist proposal. And, of course, the anti-reductionist must stand ready to consider other reductionist accounts if they are proposed, and to show how they fail.

As I have said, the topic of the anti-reductionist considerations Wittgenstein offers in RFM 392-3 is what I called the (a)-type question: what it is to act correctly according to a given rule. Someone might accept that we cannot give a reductive answer to that question, but maintain that we can nonetheless give a non-circular, reductive answer to the (b)-type question: what it is to follow a particular rule, rather than merely acting in accordance with it. That is a possible position in logical space. But, as I read him, it is not Wittgenstein's position. His approach to the (b)-type question is as resolutely anti-reductionist as is his approach to the (a)-type question. ${ }^{13}$

\section{Language-Games in The Brown Book}

I have claimed that, when Wittgenstein says that the meaning of a word is its use in the language, the notion of use has to be understood in an anti-reductionist way. As I have noted, however, many commentators disagree. And the language-games described in the Brown Book are sometimes cited as evidence of Wittgenstein's treating the relation between meaning and use in broadly reductive terms. So I want to consider a representative Brown Book example that might seem to support a 
W Child - 'We can go no further': Meaning, Use, and the Limits of Language - in H. Appelqvist (ed.) Wittgenstein and the Limits of Language, Abingdon: Routledge, 2020, pp. 93-114.

reductionist reading of Wittgenstein. I shall show how it can be accommodated within the antireductionist interpretation I am advocating.

Wittgenstein writes:

Consider this language game: A sends B to various houses in their town to fetch goods of various sorts from various people. A gives $B$ various lists. On top of every list he puts a scribble, and $B$ is trained to go to that house on the door of which he finds the same scribble, this is the name of the house. In the first column of every list he then finds one or more scribbles which he has been taught to read out. When he enters the house he calls out these words, and every inhabitant of the house has been trained to run up to him when a certain one of these sounds is called out, these sounds are the names of the people. He then addresses himself to each one of them in turn and shows to each two consecutive scribbles which stand on the list against his name. The first of these two, people in that town have been trained to associate with some particular kind of object, say, apples. The second is one of a series of scribbles which each man carries about him on a slip of paper. The person thus addressed fetches say, five apples. The first scribble was the generic name of the objects required, the second, the name of their number.

What now is the relation between a name and the object named, say, the house and its name? I suppose we could give either of two answers. The one is that the relation consists in certain strokes having been painted on the door of the house. The second answer I meant is that the relation we are concerned with is established, not just by painting these strokes on the door, but by the particular role which they play in the practice of our language as we have been sketching it. - Again, the relation of the name of a person to the person here consists in the person having been trained to run up to someone who calls out the name; or again, we might say that it consists in this and the whole of the usage of the name in the language-game. (BB 172)

On one reading, this passage and others like it show Wittgenstein taking a broadly reductive approach to meaning. His idea, on this interpretation, is that a sign's being the name of something a house, a person, a kind of fruit, a number - consists in the existence of an appropriate pattern of non-semantic behaviour involving that sign. Thus, when Wittgenstein describes 'the usage' of the name, he avoids characterizing that usage in semantic terms. He does not talk about such actions as using a scribble as the name of a particular person, or using it to call someone ' $N N^{\prime}$ ', or to say something about someone. On the contrary, he confines himself to describing simple, non-semantic actions and interactions between people. It is, on this reading, the role of a sign in such patterns of simple, non-semantic behaviour that is constitutive of its being used as a name.

If we accept that interpretation of the Brown Book passage, there is a question about how far the reductive account is supposed to go. Wittgenstein's description of the use of the scribbles includes such phenomena as people calling out words, running up to someone, addressing themselves to other people, fetching apples, and so on. Those characterizations may be nonsemantic. But, on the face of it, they are not non-intentional; for calling out words, running up to people, and the rest are intentional actions. So if Wittgenstein is gesturing at a reductive account of meaning, the reduction in question will be a limited one; it will not yield an account of facts about meaning in non-intentional terms.

In my view, however, the Brown Book passage is not proposing a reductive account of meaning at all. What Wittgenstein is describing in this example is not our language but a simpler and more primitive language-game. In our community, there are facts of these kinds: someone's saying that someone is such-and-such; someone's calling someone ' $\mathrm{NN}^{\prime}$ '; someone's using the sign ' $N N^{\prime}$ ' as a person's name; and so on. In the Brown Book language-game, by contrast, there are no semantic facts of that kind: the pattern of sign-involving activity that Wittgenstein describes is too basic and primitive to be a practice of giving and using names. So, though he describes the scribbles as 'names' in the context of the example, they are not what we would call 'names'. But they play a role in the simple language-game that is analogous to the role of names in our language. So we can 
use the simple language-game to make a point about the relation between signs and things that is equally true of the relation between names and objects in our language. In particular, the point of the example is that the relation between a sign and a thing is not constituted by anything 'static': a scribble being painted on a house; the fact that someone has been trained to run up when a particular sound is called out; and so forth. Rather, it essentially involves something 'dynamic': the role of the scribble in the whole practice of the language-game. ${ }^{14}$ Wittgenstein makes that point in connection with the primitive, scribble language-game. But the point applies equally well to the relation between a full-blown name in our language and the thing or person whose name it is. The simple language-game is introduced as a way of making that point about our language.

That way of understanding the Brown Book passage fits well with what Wittgenstein says about the role of language-games in his method:

Our clear and simple language-games are not preliminary studies for a future regimentation of language - as it were, first approximations, ignoring friction and air resistance. Rather, the language-games stand there as objects of comparison which, through similarities and dissimilarities, are meant to throw light on features of our language. (PI §130)

The scribble example is a 'clear and simple language-game'. Wittgenstein is not offering it as a preliminary stage in a prospective full account of language. He is not suggesting that we can build up from the simple case to give an account that shows how the relation between name and object in our language is constituted by a sufficiently complex pattern of the kinds of simple, non-semantic action that he describes. Rather, he is using the scribble example as an 'object of comparison' to make a point about the simple case that is true of our language, too. Seen in that light, the scribble example offers no evidence in favour of the suggestion that Wittgenstein takes a reductionist view of meaning and use.

\section{Supervenience and the Avoidance of Pleonasm}

I have argued that Wittgenstein is an anti-reductionist: facts about meaning, rules, and rulefollowing, he thinks, are sui generis; they cannot be reduced to, or explained in terms of, facts about anything else. On the other hand, he thinks that there is a close relation between semantic and normative facts on the one hand, and lower-level, non-semantic and non-normative facts on the other; if the lower-level facts were very different then the semantic and normative facts would be different, too. And he aims to say something substantive and non-pleonastic in response to constitutive questions about meaning and rules. These latter aspects of Wittgenstein's treatment distinguish his view from the simplest, most flat-footed kinds of anti-reductionism. How should we understand this element of his position?

6.i Though Wittgenstein is clearly opposed to attempts to reduce facts about meaning and rulefollowing to more basic facts, he is equally clear that there is an important relation between semantic and normative facts, on the one hand, and facts characterized in non-semantic, nonnormative, terms on the other hand. For instance:

What if we said that mathematical propositions were prophecies in this sense: they predict what result members of a society who have learnt this technique will get in agreement with other members of the society? ' $25 \times 25=625$ ' would thus mean that men, if we judge them to obey the rules of multiplication, will reach the result 625 when they multiply $25 \times 25$. -

That this is a correct prediction is beyond doubt; and also that calculating is in essence founded on such predictions. That is to say, we should not call something 'calculating' if we could not make such a prophecy with certainty. This really mean: calculating is a technique. And what we had said pertains to the essence of a technique. (RFM III-66)

One message of that passage is that the existence of a practice of calculating requires the existence of a pattern of empirical regularities in behaviour, non-normatively characterized. If it weren't true that people who have been through the normal training in calculation, and have been accepted as 
W Child - 'We can go no further': Meaning, Use, and the Limits of Language - in H. Appelqvist (ed.) Wittgenstein and the Limits of Language, Abingdon: Routledge, 2020, pp. 93-114.

competent in multiplication, by and large give the result ' 625 ' when asked what 25 x 25 equals, there would be no practice of multiplying in our community. ${ }^{15}$

It is natural to express Wittgenstein's view in terms of supervenience. Facts about rulefollowing cannot be reduced to, or explained in terms of, non-normative facts about people's behaviour; but they do supervene on such non-normative facts. That is to say, two worlds cannot differ with respect to facts about rule-following without differing in some non-normative respect; and if two worlds are alike in all non-normative respects, they must also be alike with respect to all the facts about rule-following. In the same way, semantic facts cannot be reduced to, or explained in terms of, non-semantic facts; but they do supervene on non-semantic facts. ${ }^{16}$

6.ii We can reach the same understanding of Wittgenstein's position from a different direction, by considering the picture of the nature and status of common-sense psychology that he offers in Last Writings on the Philosophy of Psychology volume II.

Wittgenstein presents common-sense psychology as a sui generis scheme of description and explanation: a scheme that we all use when we talk and think about ourselves and others. And, he thinks, we should accept such talk at face value and understand it on its own terms. In his words:

I look at this language-game as autonomous. I merely want to describe it, or look at it, not justify it. (LW II 40)

The descriptions and explanations of common-sense psychology cannot be reduced to, or correlated with, or explained in terms of, those of the physical sciences. But that does nothing to undermine them or to threaten their truth. For common-sense psychology does not depend for its legitimacy on the possibility of any such reduction or correlation. It is, as Wittgenstein says, autonomous.

At the same time, he insists that the truth of psychological descriptions and explanations does not require the existence of anything that is not provided for by the physical sciences. 'Mental', as Wittgenstein puts it, 'is not a metaphysical, but a logical, epithet' (LW II 63). Physical investigation could in principle give a complete account of the physical make-up of a person, and of the physical processes that take place within a person and produce the movements of their body, including the movements involved in speaking: an account that did not mention thoughts, intentions, experiences and so on. ${ }^{17}$ But the possibility of such a physical account does not undermine the descriptions and explanations of common-sense psychology. For common-sense psychology does not depend on the assumption that human behaviour is produced by non-physical mechanisms; it is compatible with accepting that human beings are exhaustively composed of physical matter.

What emerges from Wittgenstein's comments about the status of common-sense psychology is the following picture. On the one hand, common-sense psychology is a sui generis scheme for describing and explaining the behaviour of human beings. It cannot be reduced to, or correlated with, the physical scheme. On the other hand, common-sense psychology does not introduce any distinctive, non-physical ontology. If we fix all the physical facts, we fix all the facts, including the facts of common-sense psychology - and the facts about meanings and rules. That way of putting things would not normally be associated with Wittgenstein. But, I think, it is completely faithful to his views. And it is of a piece with the ideas about supervenience sketched in 6.i.

6.iii A third way of approaching the character of Wittgenstein's anti-reductionism is to consider how he responds to his own constitutive questions about rules and meanings.

What does it take for someone to be following a rule rather than merely conforming to a rule? Wittgenstein's response to that question is not simply to say, pleonastically, that what it takes for someone to be following a particular rule is, precisely, for them to be following that rule. He tries to say something more informative than that. We can illustrate the point with an example. Wittgenstein writes:

Let us consider very simple rules. Let the expression be a figure, say this one: 
W Child - 'We can go no further': Meaning, Use, and the Limits of Language - in H. Appelqvist (ed.) Wittgenstein and the Limits of Language, Abingdon: Routledge, 2020, pp. 93-114.

\section{$|--|$}

and one follows the rule by drawing a straight sequence of such figures (perhaps as an ornament).

$$
|--||--||--||--||--|
$$

Under what circumstances should we say: someone gives a rule by writing down such a figure? Under what circumstances: someone is following this rule when he draws that sequence? It is difficult to describe this.

If one of a pair of chimpanzees once scratched the figure $|--|$ in the earth and thereupon the other the series $|--||--|$ etc., the first would not have given a rule nor would the other be following it, whatever else went on at the same time in the minds of the two of them.

If however there were observed, e.g., the phenomenon of a kind of instruction, of showing how and of imitation, of lucky and misfiring attempts, of reward and punishment and the like; if at length the one who had been so trained put figures which he had never seen before one after another in sequence as in the first example, then we should probably say that the one chimpanzee was writing rules down, and the other following them (RFM 345).

The behaviour of the chimpanzees can be described in terms that do not presuppose that a rule is being given and followed; the first chimpanzee scratches the figure $|--|$ in the earth and the second scratches the series $|--||--|$ etc. If that is just a one-off occurrence, Wittgenstein says, no rule has been given or followed. When it happens in the right kind of context, however, we do have a case of giving and following a rule. But what exactly are the circumstances under which we should say that a rule is being given and followed? The simplest anti-reductionist response would be to say merely that the circumstances under which we should say that a rule is being given and followed are just those in which people (or chimpanzees) are participating in a practice of giving and following rules. But that is not what Wittgenstein says. Instead, he tries to say something genuinely illuminating and non-pleonastic about what it takes for there to be a custom of giving and following such rules, and what it takes for two people (or chimpanzees) to be participants in such a practice. In particular, he suggests that the existence of a practice of following rules involves the existence of a whole pattern of rule-involving activity. Some of the activities he mentions in RFM 345 are particular to the situation of learning: instruction, showing how, imitation, etc. Others are more general: reward and punishment, for instance. But the most basic feature of rule-following, which is implicit in all the activities Wittgenstein mentions, is that giving or following rules involves treating or understanding actions as being correct or incorrect. The idea of understanding an action as correct or incorrect is no more basic than the idea of following a rule itself. ${ }^{18}$ So Wittgenstein's comments do not promise a reductive account of what it is for people (or chimpanzees) to be giving and following rules. But they do offer genuine illumination by describing, in non-reductive terms, the kind of complex structure of activities that he takes to be required if something is to count as an instance of giving or following a rule. ${ }^{19}$

We can see the same features in Wittgenstein's non-reductionist treatment of the relation between meaning and use. At one point in the Brown Book, Wittgenstein imagines an objection to some of the cases he describes:

It is an important remark concerning this example and others which we give that one may object to the description which we give of the language of a tribe, that in the specimens we give of their language we let them speak English, thereby already presupposing the whole background of the English language, that is, our usual meanings of the words. Thus if I say that in a certain language there is no special verb for 'skipping', but that this language uses instead the form 'making the test for throwing the boomerang', one may ask how I have characterized the use of the expressions, 'make a test for' and 'throwing the boomerang', to be justified in substituting these English expressions for whatever their actual words may be. To this we must answer that we have only given a very sketchy description of the practices 
W Child - 'We can go no further': Meaning, Use, and the Limits of Language - in H. Appelqvist (ed.) Wittgenstein and the Limits of Language, Abingdon: Routledge, 2020, pp. 93-114.

of our fictitious languages, in some cases only hints, but that one can easily make these descriptions more complete. (BB 102)

The 'more complete' descriptions would spell out how the words or phrases in question are used, in a way that explained why, or how, they have the same meanings as the relevant English expressions. Thus:

whether a word of the language of our tribe is rightly translated into a word of the English language depends upon the role this word plays in the whole life of the tribe; the occasions on which it is used, the expressions of emotion by which it is generally accompanied, the ideas which it generally awakens or which prompt its saying, etc., etc. As an exercise ask yourself: in which cases would you say that a certain word uttered by the people of the tribe was a greeting? In which cases should we say it corresponded to our 'Goodbye', in which to our 'Hello'? (BB 103)

We can say, of course, that a word of an unfamiliar language corresponds to our word 'Goodbye' just in case it is used by speakers of that language in the same way that we use the word 'Goodbye': or, more simply, if it is used by those speakers to mean Goodbye. But can we get beyond pleonastic statements like that? Can we spell out, in non-semantic, non-intentional terms, exactly how the word 'Goodbye' is used in our language and, therefore, how a word in another language must be used in order to be rightly translated as 'Goodbye'? There is nothing in Wittgenstein's discussion to suggest that we can. But he does think that, when we consider particular cases, we can say something to justify particular assignments of meaning in a way that respects the constraint of antireductionism whilst going beyond the kinds of pleonastic formulation just mentioned.

We can illustrate that point with another part of the same discussion. Wittgenstein imagines a case in which 'the men of a tribe are subjected to a kind of medical examination before going into war'. An examiner puts them through tests involving various physical activities: skipping, lifting weights, etc. Wittgenstein asks what justifies translating some expression of these people's language by the English expression 'Go through the test for throwing the boomerang'. He offers the following as the kind of account that would justify such a translation:

The examiner uses orders for making the men go through the tests. These orders all begin with one particular expression which I could translate into the English words, 'Go through the test'. And this expression is followed by one which in actual warfare is used for certain actions. Thus there is a command upon which men throw their boomerangs and which therefore I should translate into, 'Throw the boomerangs'. Further, if a man gives an account of the battle to his chief, he again uses the expression I have translated into 'throw a boomerang', this time in a description. (BB 102-3)

In that passage, Wittgenstein does not say merely that what justifies translating an expression by the English words 'go through the test for throwing the boomerang' is that people use it to mean go through the test for throwing the boomerang. He does something to unpack what it takes for an expression to be used with that meaning: pointing to the kinds of feature that would in fact be appealed to by an anthropologist or a radical interpreter in coming to understand an unfamiliar language. Thus, he stresses that the expression contains a form of words that is an ingredient in a range of different orders; and that it contains another form of words that is used for the action of throwing boomerangs in descriptions as well as commands. But there is no suggestion in those comments that we could explain what it is for an expression to mean 'throw a boomerang' in entirely non-semantic, non-intentional terms. Indeed, Wittgenstein simply helps himself to the semantic notions of an expression's being 'used for' a certain action, and of an expression's being used in a 'command' and in a 'description'. It is true that he then goes on to say something more about the kind of circumstances that would justify the judgement that a particular expression is 'used for', or refers to, the action of throwing a boomerang; he mentions the fact that, when the expression is used in a command, it is followed by people throwing their boomerangs. But that fact does not come close to supplying a reductive account of meaning. (As before, the fact that the utterance of an expression is regularly followed by people throwing boomerangs is neither necessary 
nor sufficient for it to mean 'throw a boomerang'.) Similarly, he goes on to say something about what it takes for an utterance to be a command or a description:

what characterizes an order as such, or a description as such, or a question as such, etc., is as we have said - the role which the utterance of these signs plays in the whole practice of the language.

But there is no indication that the distinctive role that characterizes an utterance as an order, or a description, or a question can be specified in wholly non-semantic, non-intentional terms.

The picture of the relation of meaning and use that we get from this Brown Book discussion

is this. What it takes for an expression of a language to have a given meaning is for it to be used in a particular way. The relevant way of using the expression cannot be spelled out in wholly nonsemantic, non-intentional terms. But we can say something more about the meaning-constituting use of an expression than simply to repeat the pleonastic formulation that, for an expression to mean, say, 'Goodbye' is for it to be used to mean Goodbye. That is the point that emerges from Wittgenstein's reflections on what would justify us in translating an unfamiliar expression by a particular English word or words. His view of the relation between meaning and use, like his view of rule-following, is an anti-reductionist one. But it is not the crudest kind of anti-reductionism. Facts about meaning and rules are not completely independent of non-semantic, non-normative facts; on the contrary, they supervene on them. And we are not confined to making pleonastic claims when we say how a word must be used in order to have a given meaning, or when we describe the conditions under which someone counts as following a rule.

6.iv I have argued that Wittgenstein's position about meaning and rules combines antireductionism with a willingness to go beyond merely pleonastic statements about meaning and use or about rules and rule-following. That message may seem uncontroversial. But neither element is universally accepted and both deserve emphasis. The anti-reductionist nature of Wittgenstein's treatment needs emphasis because some readers continue to see his view of meaning and rules as a form of reductionism. ${ }^{20}$ And it is equally important to emphasize the non-pleonastic nature of his treatment, and his acceptance that facts about meaning and rules are grounded in, and supervene on, non-semantic, non-normative facts. One reason why some philosophers reject antireductionism about meaning and rules is the thought that, unless some form of reductionism were true, the existence of meaning and rules would conflict with a reasonable, naturalistic view of the world; it would imply the kind of Fregean non-naturalism that Wittgenstein plainly rejects. But that thought is mistaken. Wittgenstein's treatment shows how facts about meaning and rules can be grounded in non-semantic, non-normative facts without being reducible to, or explicable in terms of, anything non-semantic or non-normative. ${ }^{21}$ 
W Child - 'We can go no further': Meaning, Use, and the Limits of Language - in H. Appelqvist (ed.) Wittgenstein and the Limits of Language, Abingdon: Routledge, 2020, pp. 93-114.

\section{$\underline{\text { References }}$}

Boghossian, Paul 1989. "The Rule-Following Considerations". Mind, 98, 507-49.

Child, William 2011. Wittgenstein. Abingdon: Routledge.

Child, William 2019. "Meaning, Use, and Supervenience", in J. Conant and S. Sunday eds., Wittgenstein on Objectivity, Intuition, and Meaning, Cambridge: Cambridge University Press.

Ginsborg 2011a "Inside and Outside Language: Stroud's Nonreductionism About Meaning", in J. Bridges, N. Kolodny and W-H Wong eds., The Possibility of Philosophical Understanding: Reflections on the Thought of Barry Stroud, Oxford: Oxford University Press, 147-181.

Ginsborg 2011b "Primitive Normativity and Skepticism about Rules". Journal of Philosophy, 108, 227-254.

Ginsborg 2012 "Meaning, Understanding and Normativity". Proceedings of the Aristotelian Society Supplementary Volume, 86, 127-46.

Horwich, Paul 2012. Wittgenstein's Metaphilosophy. Oxford University Press.

Kripke, Saul 1982. Wittgenstein on Rules and Private Language. Oxford: Blackwell.

McDowell, John 1984. "Wittgenstein on Following a Rule". Synthese, 58, 325-63.

McGinn, Colin 1984. Wittgenstein on Meaning. Oxford: Blackwell.

Snowdon, Paul 2018 "Wittgenstein and Naturalism", in K. Cahill and T. Raleigh eds., Wittgenstein and Naturalism, Abingdon: Routledge, 15-32.

Stroud, Barry 2000. Meaning, Understanding, and Practice: Philosophical Essays. Oxford University Press.

Stroud, Barry 2012. "Meaning and Understanding", in J. Ellis and D. Guevara eds., Wittgenstein and the Philosophy of Mind. Oxford University Press, 19-36. 
W Child - 'We can go no further': Meaning, Use, and the Limits of Language - in H. Appelqvist (ed.) Wittgenstein and the Limits of Language, Abingdon: Routledge, 2020, pp. 93-114.

\section{$\underline{\text { Notes }}$}

I Wittgenstein's simple statement of the point is a bit too simple. For in cases of synonymy or analytic equivalence, we can pick out the fact that corresponds to a given sentence without repeating that very sentence. We can say, for instance, that the fact that corresponds to the sentence 'John is a bachelor' is the fact that John is an unmarried man. The same is true when we use one language to talk about another. That complicates Wittgenstein's point, but it does not undermine his fundamental intuition.

2 For a related discussion of the limits of language theme in Wittgenstein's post-Tractatus writings, and its relation to his anti-reductionism about meaning and rules, see Stroud 2012.

3 Wittgenstein restricts this 'explanation' to 'a large class of cases of the employment of the word "meaning". We can focus on that class of cases, leaving aside those to which Wittgenstein's explanation is not intended to apply.

${ }^{4}$ For other statements of Stroud's anti-reductionism about meaning, see Stroud 2000, pp. ix, I30, 91-2. For other anti-reductionist readings of Wittgenstein on meaning and use, see McGinn 1984, McDowell 1984, Child 201 I pp. I0I-104, II4-2I. Boghossian 1989 advocates anti-reductionism about meaning as the best response to Kripke's Wittgenstein; he does not take a stand on Wittgenstein's own position.

${ }^{5}$ For a similar message, see RFM 323 b-c.

${ }^{6}$ For other well-known statements of anti-reductionism, see e.g. PI $\S \S 124,126$.

7 See Snowdon 2018, 23-25 for similar remarks, with which I am broadly sympathetic.

8 I do not suggest that this form of communitarianism is a plausible account of what the correct following of a rule consists in. I state it only for the sake of argument.

9 That assumes that using words involves following rules. It seems clear that Wittgenstein accepts that assumption: 'Following according to the rule is FUNDAMENTAL to our language-game. It characterizes what we call description' (RFM VI-28).

10 See Ginsborg 20I Ia 163-6 for related considerations against an argument for anti-reductionism about meaning and understanding that she plausibly ascribes to Stroud.

II Wittgenstein puts the point in epistemic terms ('it is no more certain ...'). But I take his fundamental point to be constitutive rather than epistemic.

12 Notice the close relation between these two arguments against reductive accounts and the main arguments that Kripke's Wittgenstein gives against dispositional analyses of meaning: that our dispositions are finite and include dispositions to make mistakes; and that no dispositional account can capture what Kripke calls the normative dimension of rules and meaning. (See Kripke 1982, PP. 22-37.)

13 I offer some support for this claim in section 6.iii below.

14 For the idea that meaning requires something dynamic, not something static or stationary, see e.g. PG 55, 100, I49; LFM I84.

15 For similar passages, see e.g. RFM 325, 327, 355.

16 For discussion and defence of this supervenience claim, and its attribution to Wittgenstein, see Child 2019.

17 For this point, see e.g. LW II 3I, 36, 40.

18 I disagree here with Hannah Ginsborg, who argues that there is a primitive way of taking a performance to be appropriate in its context, which is independent of any prior grasp of meaning or rules (see Ginsborg 20I la, 20I l b, 20I2). She appeals to this 'consciousness of ... primitive appropriateness' (201 I, p. 248) to offer a 'partly reductionist' explanation of facts about meaning and rule-following (20I I, p. 230). I hope to discuss this interesting proposal elsewhere.

19 This paragraph is based on Child 2019, pp. xx-xx.

20 As noted earlier, Horwich 2012, Snowdon 2018 are recent examples. Ginsborg also suggests that Wittgenstein's account is not a fully anti-reductionist one.

${ }^{21}$ Earlier versions of this material were presented the conferences 'Wittgenstein and the Limits of Language' at the University of Helsinki in 2016 and 'Wittgenstein: The Place of Normativity in a Naturalistic World' at the University of Ottawa in 2018. I am grateful to the participants on those occasions for very helpful comments and discussion. 